\title{
EXPERIMENTAL STUDY OF VERMICOMPOST DRYING PROCESS
}

\author{
Aivars Kak̦ītis, ImantsNulle, Olafs Vronskis \\ Latvia University of Agriculture \\ aivars.kakitis@1lu.lv, imants.nulle@1lu.lv, olafs.vronskis@1lu.lv
}

\begin{abstract}
Biohumus is widely used for various vegetable productions. However, its use is difficult in places such as recreation, sports, golf, and football fields. Humus uneven distribution across the field promotes grass growth at different speeds. The result is not acceptable. Therefore, to develop vermicomposting end product usability work is needed in several directions. One of the directions is to develop the possibility of humus evenly spreading across the field. It can be done developing new or improving the existing technologies, which allow doing it with minimal impact on product quality. Granular vermicompost can be called concentrated fertilizer, because the recycling process reduces the volume of material more than 10 times, due to water removal and material thickening while extruding. It is therefore necessary to examine the humus moisture content and determine the energy needed for drying it. Given that vermicompost is a biologically active material, the drying must be carried out at the lowest possible temperature. It is not recommended to increase the drying temperature above $35^{\circ} \mathrm{C}$. The aim of this research is to determine the drying rates of vermicompost in different temperatures of the drying agent and avoid overdrying. The drying rate is defined as the variation of the moisture content with respect to the time. The studies showed that the maximum of the drying speed was observed at the beginning of the process and reached $0.86 \% \cdot \mathrm{min}^{-1}$ in the drying temperature $64{ }^{\circ} \mathrm{C}$. Decreasing of the drying temperature decreases the drying speed to $0.59 \% \cdot \mathrm{min}^{-1}$.
\end{abstract}

Keywords: vermicompost, drying, drying rate, drying temperature.

\section{Introduction}

Vermicomposting is a special type of composting, which uses certain earthworms. They accelerate decomposition processes during vermicomposting [1]. The main qualities of vermicomposts that make them superior for organic soil amendments are their excellent biological properties. These properties have been linked not only to nutrient cycling in the soil or plant growth media, but also to their ability to supply crops with plant growth hormones such as auxins, gibberellins, and cytokinins and also fulvic and humic acids functioning as plant growth regulators. Vermicomposts are rich in bacteria, actinomycetes, fungi, and cellulose-degrading bacteria [2].

Microorganisms and earthworms are active in a temperature range of $10-32{ }^{\circ} \mathrm{C}$. The moisture contents of vermicomposts should be between 75 and $90 \%$ during processing, but the moisture contents may vary widely in finished vermicomposts, probably without substantially affecting their overall quality or storage potential. Nevertheless, very wet materials can be expensive to transport because of excess weight and can be difficult or messy to handle. Of course, moisture contents can also have a major impact on the value of vermicomposts that are sold by weight. Hence, it has become more common to market vermicomposts by volume. At the same time, materials that are too dry may have problems with rewetting and may suffer some reduction in plant disease suppressiveness due to changes in the composition of the microbial community, and this may affect other beneficial qualities dependent on the structure and composition of the soil food web. Generally, acceptable moisture contents range from 30 to $50 \%$ [2].

One of the most difficult technical obstacles to solve in the production of vermicompost is drying the end product. It is necessary to reduce the initial water content of 75-80\% to about 50-55 \%. Less than $45 \%$ moisture means that the casts may become dusty and gray, which diminishes the microbial activity and changes its attractive black color. It does not recover its texture after rewetting [2]. Investigation of different air heating solar collector constructions showed that the inflatable solar air heating collector (solar greenhouse collector) is easy to make, operate and to derange its construction [3]. It works well in Latvian climatic conditions. There are also many types of solar greenhouse dryers studied by several authors. Effective drying is accomplished with a combination of heat and air movement [4]. The air flow and temperature of solar greenhouse dryers could be set to suggestible temperature range also for vermicompost drying. For some product drying process direct sunlight is not recommended [4]. It could be very important also for vermicompost drying to save its biological texture. Therefore, in compost drying technologies it should be taken into account. To select the vermicompost drying parameters it is necessary to determine the drying rate changes depending on the 
temperature of the drying agent. Drying rate is defined as the moisture content change depending on the drying time. The drying process can theoretically be divided into the following three stages [5].

1. Increase of the temperature of the product to desiccate;

2. The unbound water evaporation from the surface of the material particles. The process exists while the process of evaporation takes place up to point of "critical content water". In this period the drying rate is constant;

3. Final phase. Drying process in this period slows down due to the unbound water absence on the particle surface.

In order to preserve the biological activity of vermicompost, in drying it is not recommended to heat it more than $30-35{ }^{\circ} \mathrm{C}$. In the previous research it was found that in order to ensure the quality of the granulation process the humidity of vermicompost should be in the range of 20-25\% [6].The aim of this research is to determine the drying rates of vermicompost in different temperatures of the drying agent to develop an efficient drying technology, avoid overdrying and decreasing of biological activity of vermicompost. The experiments were performed at two constant incoming air temperatures $\left(64^{\circ} \mathrm{C}\right.$ and $\left.38^{\circ} \mathrm{C}\right)$ to determine heating up of the mass during drying and to assess the drying efficiency.

\section{Materials and methods}

The laboratory experiments were carried out at the Faculty of Engineering of the Latvia University of Agriculture. In the drying experiments natural vermicompost produced in the company Ltd. Bioorganic Earthworm Compost was used. Samples were prepared from the vermicompost produced at different times in the year 2015. The samples with a mass $5 \mathrm{~kg}$ of the vermicompost were prepared for drying experiments. Initial and final moisture content of vermicompost was determined using the oven drying method described at the standard LVS EN 15414 3. To determine the initial and final moisture, the samples were taken with a mass of 30 grams. The samples were weighted before and after the experiment using digital scales Sartorius GM 312 with full scale $300 \pm 0.01 \mathrm{~g}$. The samples were fully dried at $105^{\circ} \mathrm{C}$ temperature and weighted again. Initial and final moisture were calculated using equation (1):

$$
w=1-\frac{m_{2}}{m_{1}} \cdot 100,
$$

where $w$-moisture content, \%;

$m_{2}$ - sample mass after drying, g;

$m_{1}-$ sample mass before drying, $\mathrm{g}$.

To determine the vermicompost drying parameters own designed chamber type dryer with forced air flow was used (Fig. 1).

The drying equipment (Fig. 1) consists of the drying chamber 7, fan 4, and heater 5 . The drying chamber 7 was hanged with flexible links to the force sensor 9 for uninterrupted mass change measurements. Air temperature was recorded in the inlet of the drying chamber $-t_{1}$ (inflow temperature), and at the outlet of the chamber $-t_{2}$. The inlet air temperature was kept constant $\left(t_{1} \pm 1^{\circ} \mathrm{C}\right)$ using the temperature controller. Humidity of the drying agent is recorded at the inlet and outlet of the chamber $\left(w_{1} ; w_{2}\right)$. Room (environment) air humidity and temperature also were measured $\left(t_{i}, w_{i}\right)$. For temperature measuring platinum sensors were used. Signal conditioning was carried out using the Seneca T121 converter, which provides a measurement accuracy of $\pm 0.1^{\circ} \mathrm{C}$. Capacitive Humidity Module LinPicco ${ }^{\mathrm{TM}}$ A05 Basic with analogue output 0-5 V for air humidity measuring was used. This module provides measuring error less than $3 \%$.

For sample weight change measurement in the drying process a wire strain gauge bridge and calibrated flat bar were used. The weight measuring device provided a sensitivity of $0.1 \mathrm{~N}$. The calibration measurement error was $\pm 0.5 \%$. All sensors were connected to high resolution data logger Pico ADC24, which provides 24 bit resolution with measuring accuracy $\pm 0.1 \%$. Drying parameters were measured and stored every 2 minutes. The experiments were repeated 10 times for each of the drying mode. 
The drying parameters were determined at two temperature regimes $-64{ }^{\circ} \mathrm{C}$ and $38{ }^{\circ} \mathrm{C}$ degrees to avoid the degradation of the biologically active substances. Vermicompost layer thicknesses on the sieve tray was $60 \mathrm{~mm}$. Air flow through the drying chamber was kept constant $0.6 \mathrm{~m} \cdot \mathrm{s}^{-1}$ to avoid light particle outflows with the air flow.To decrease the drying chamber weight and weight measuring error it was made of foam plastic. Ambient temperature was kept constant $20 \pm 1.5^{\circ} \mathrm{C}$ and air humidity $34 \pm 2 \%$. Initial moisture of the samples was $51.7 \%$.

The obtained experimental results were processed using Excel data processing tools.

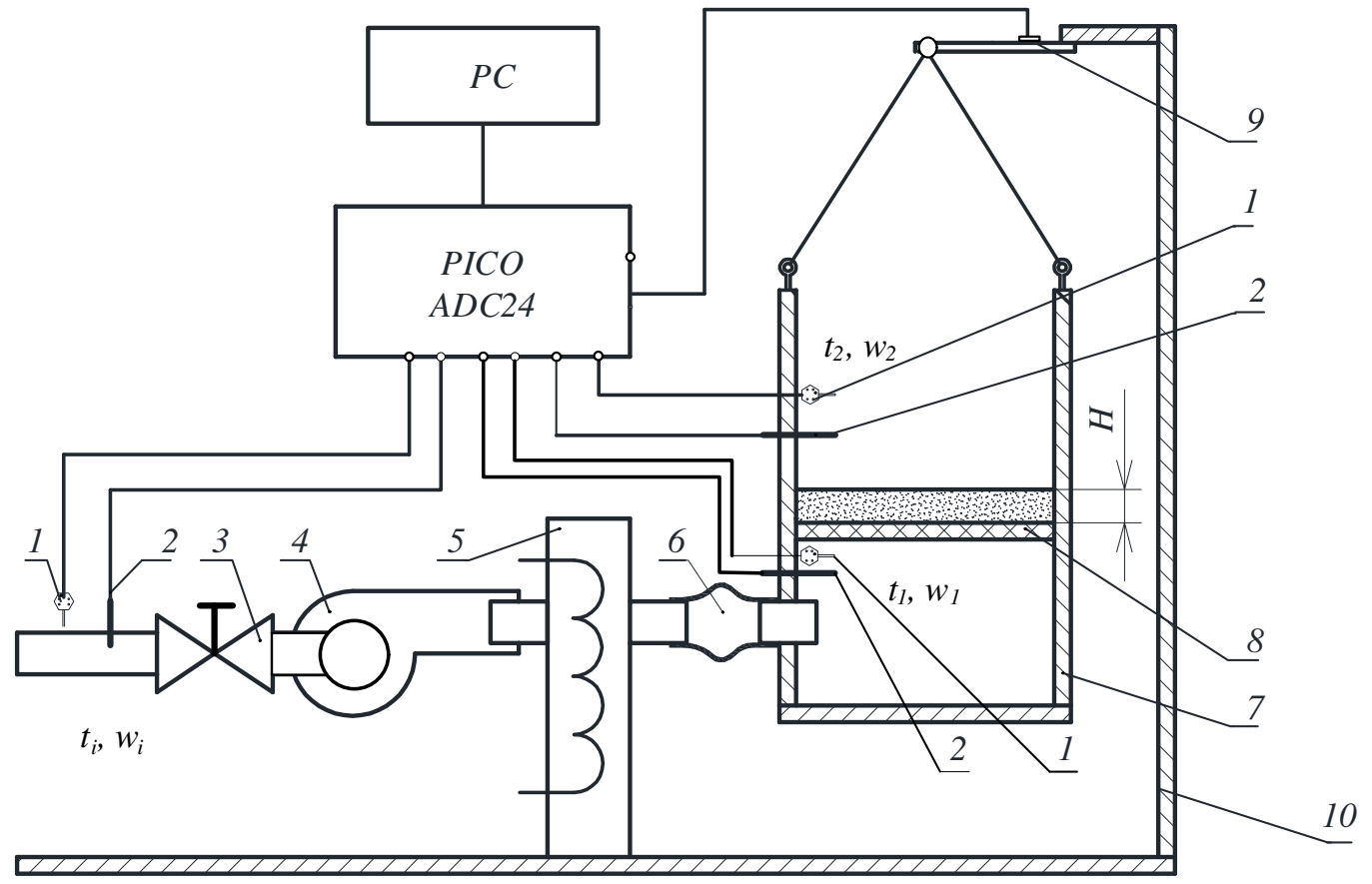

Fig. 1. Experimental drying equipment: 1 - inlet and outlet air humidity sensors; 2 - inlet and outlet air temperature sensors; 3 - air flow control valve; 4 - fan; 5 - heater; 6 - flexible air tube connection; 7 - drying chamber; 8 - sieve tray; 9 - force sensor; 10 - frame

The moisture content was calculated using the equation (2) [7]:

$$
M C_{\%}=\frac{m_{M n}}{m_{T n}} \cdot 100=\frac{m_{M(n+1)}-m_{T n}+m_{T(n+1)}}{m_{T n}} \cdot 100,
$$

where $M C_{\%}-$ moisture content in material, \%;

$m_{M n}-$ initial moisture mass in sampling period, $\mathrm{g}$;

$m_{M(n+1)}$ - final moisture mass in sampling period, $\mathrm{g}$;

$m_{T n^{-}}$initial total material mass in sampling period, $\mathrm{g}$;

$m_{T(n+1)}$ - final total material mass in sampling period, $\mathrm{g}$.

The drying rate is defined as the moisture content change in the sampling time period. It was calculated from the experimental data obtained using the equation (3)[8]:

$$
D R=\frac{\Delta M C}{\Delta t}=-\frac{M C_{2}-M C_{1}}{t_{2}-t_{1}},
$$

where $\mathrm{D} R$ - drying rate, $\% \cdot \mathrm{min}^{-1}$;

$\triangle M C$ - moisture content change in sampling period $\Delta t$;

$M C_{1}$ - initial moisture content in period, \%;

$M C_{2}$ - final moisture content in period, \%;

$t_{1}$ - start time of drying period, min;

$t_{2}-$ end time of drying period, min. 
To get positive values of the drying speed in the formula (3) the sign was changed to minus. Considering that the data were recorded every two minutes, an exact curve was obtained that describes the changes in the moisture content as a function $M C_{\%}(t)=f(t)$.Drying speed can be calculated by differentiating the acquired function:

$$
D R=-\frac{d M C_{\%}(t)}{d t} .
$$

Function $M C_{\%}(t)$ was acquired performing the regression analysis of the experimental data.

\section{Results and discussion}

In order to evaluate the parameters of the drying process during the experiment the air temperature was fixed in the inlet below the vermicompost layer $t_{1}$ and the outlet air temperature $t_{2}$ (Fig. 1). Air humidity was measured at the inlet $w_{1}$ and outlet $w_{2}$ also. By the analysis of the curves, which show the outgoing air parameters, we can conclude that the drying process can be divided into three main stages (Fig. 2).

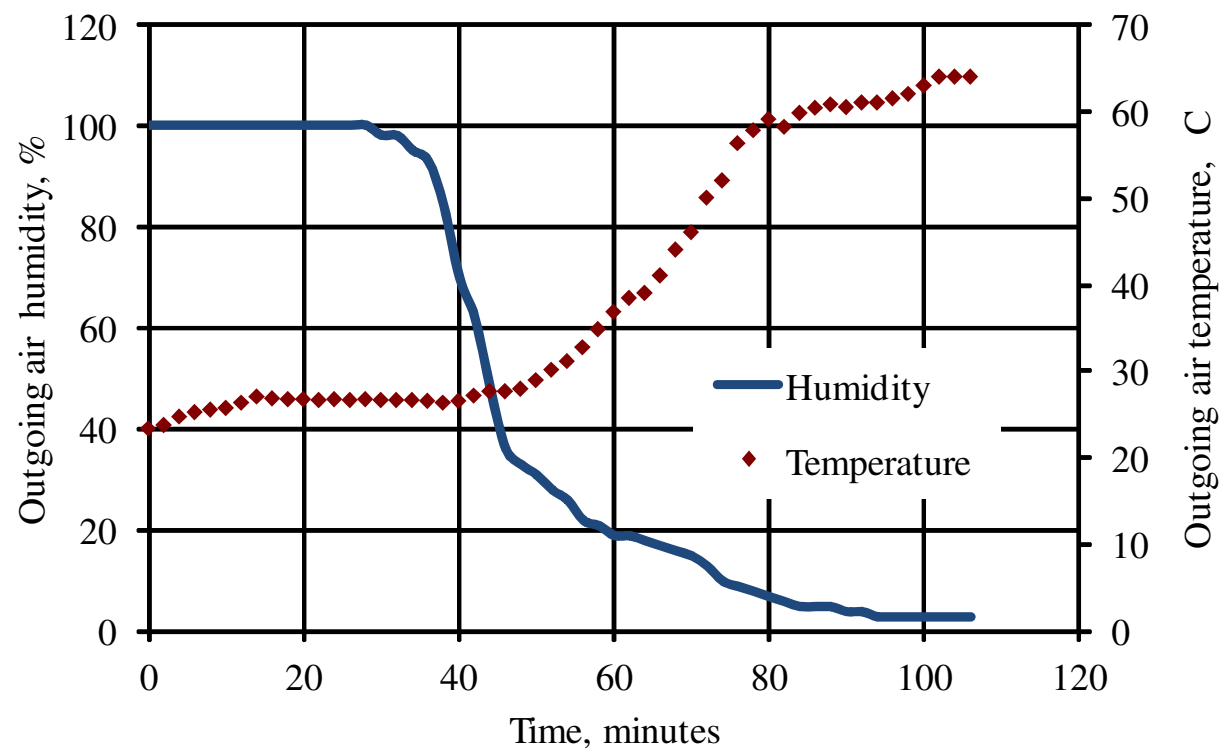

\section{Fig. 2. Temperature and moisture content of outgoing air depending on time at $64{ }^{\circ} \mathrm{C}$ of incoming air temperature}

In the first stage, from the beginning of the drying up to about 30 minutes, the outgoing air humidity was approaching $100 \%$, while the outgoing air temperature is low. This shows the intense unbound water evaporation.

The second drying stage takes from 30 minutes to about 50 minutes, the material is characterized by a rapid increase in temperature and the outgoing air humidity decreasing. At this stage, there is intensive drying of the material as evidenced by the rapid decline of the material moisture.

The third stage begins after 50 minutes. In this stage water migrates from deeper layers of the material and the moisture content decreases slowly. The outgoing air temperature increases significantly as the amount of the heat required to vaporize water decreases.

Drying vermicompost at lower temperature, the outgoing air humidity starts to decline after 12 minutes, indicating less intense water evaporation (Fig. 3).

To determine the moisture changes during drying of the material many mathematical models have been created. In the vast majority of cases exponential correlations or quadratic polynomials are used $[9,10]$. By performing the regression analysis regression equations that describe the vermicompost water content change during drying were determined. Equations were derived from the experimental data shown in Figure 4. If drying occurs at the inlet air temperature of $64^{\circ} \mathrm{C}$, the humidity change depending on the drying time is described by the equation (3):

$$
M C_{\%}=0.0047 \cdot t^{2}-0.97 \cdot t+53.6 .
$$


The coefficient of determination reaches $R^{2}=0.999$, indicating a high correlation.

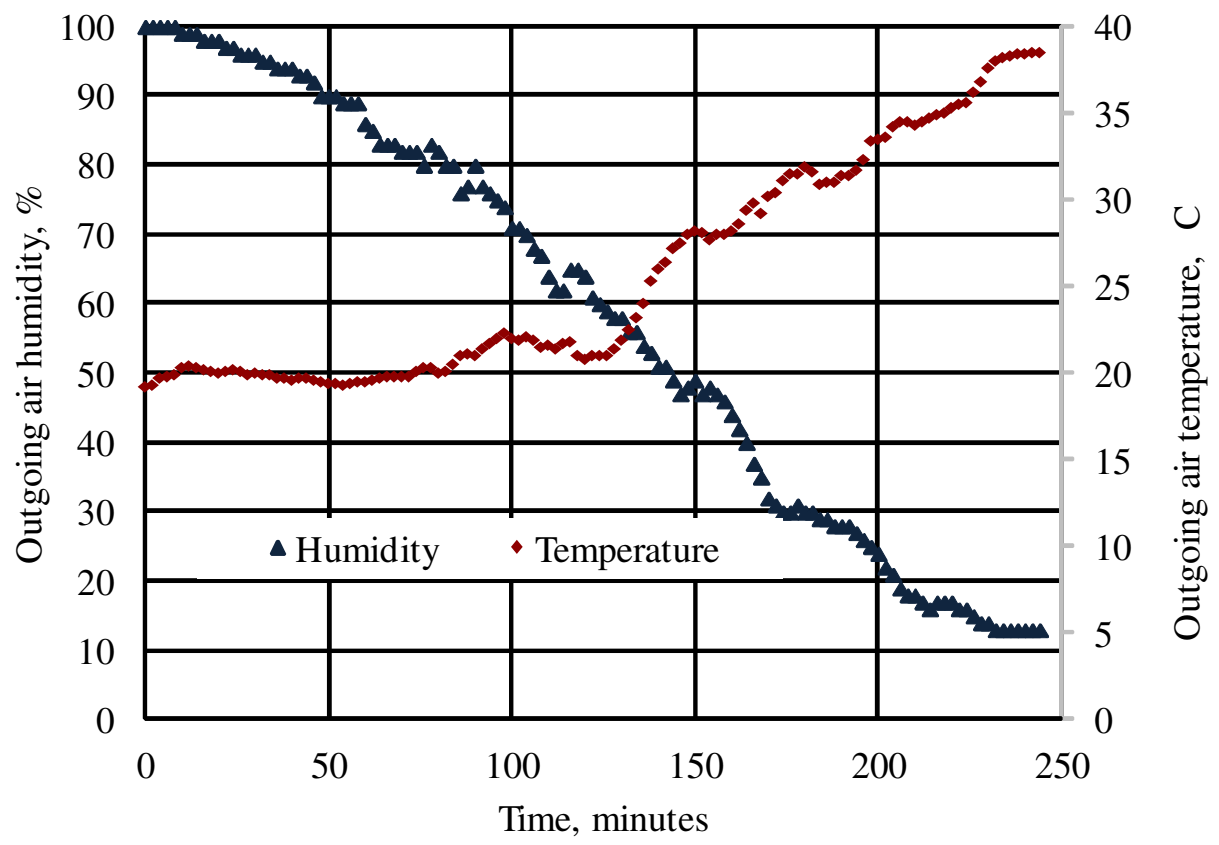

Fig. 3. Temperature and moisture content of outgoing air depending on time at $38{ }^{\circ} \mathrm{C}$ of incoming air temperature

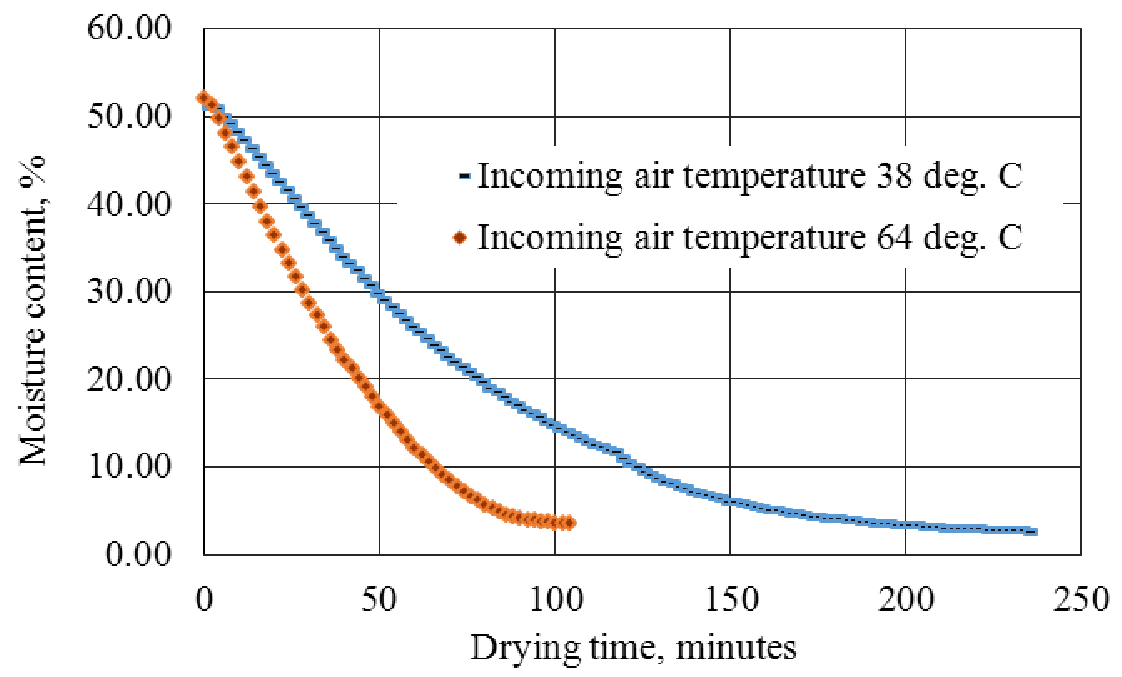

Fig. 4. Moisture change of the vermicompost depending on drying time at two temperatures of incoming air

Drying vermicompost at the incoming air temperature $38^{\circ} \mathrm{C}$ (Fig. 4), the humidity changes are accurately described by the third-order polynomial equation (4):

$$
M C_{\%}=-3 \cdot 10^{-6} \cdot t^{3}+0.0022 \cdot t^{2}-0.58 \cdot t+52.7 .
$$

The coefficient of determination $R^{2}=0.999$.

By the differentiating equation (4) the drying speed $D R$ was obtained:

$$
D R=-\frac{d M C_{\%}(t)}{d t}=9 \cdot 10^{-6} \cdot t^{2}-0.0044 \cdot t+0.58 .
$$

Comparing the experimentally obtained drying rate change (Fig. 5) and the calculated (equation 5), we can see that the results coincide with great accuracy. This is shown by the regression equation coincidence with the theoretical calculation equation (4). The coefficient of determination is $R^{2}=0.989$ (Fig. 5). We can conclude that the given method can be used to determine the drying rate 
from the equation of the moisture content changes. That calculation is valid for a period of time starting from 10 minutes. At this time from the start of drying a transition period takes place when the vermicompost layer warms up. The drying rate change during this period cannot be described by a stationary process equation. The drying rate change depending on the drying time including the transition process is displayed in Figure 6.

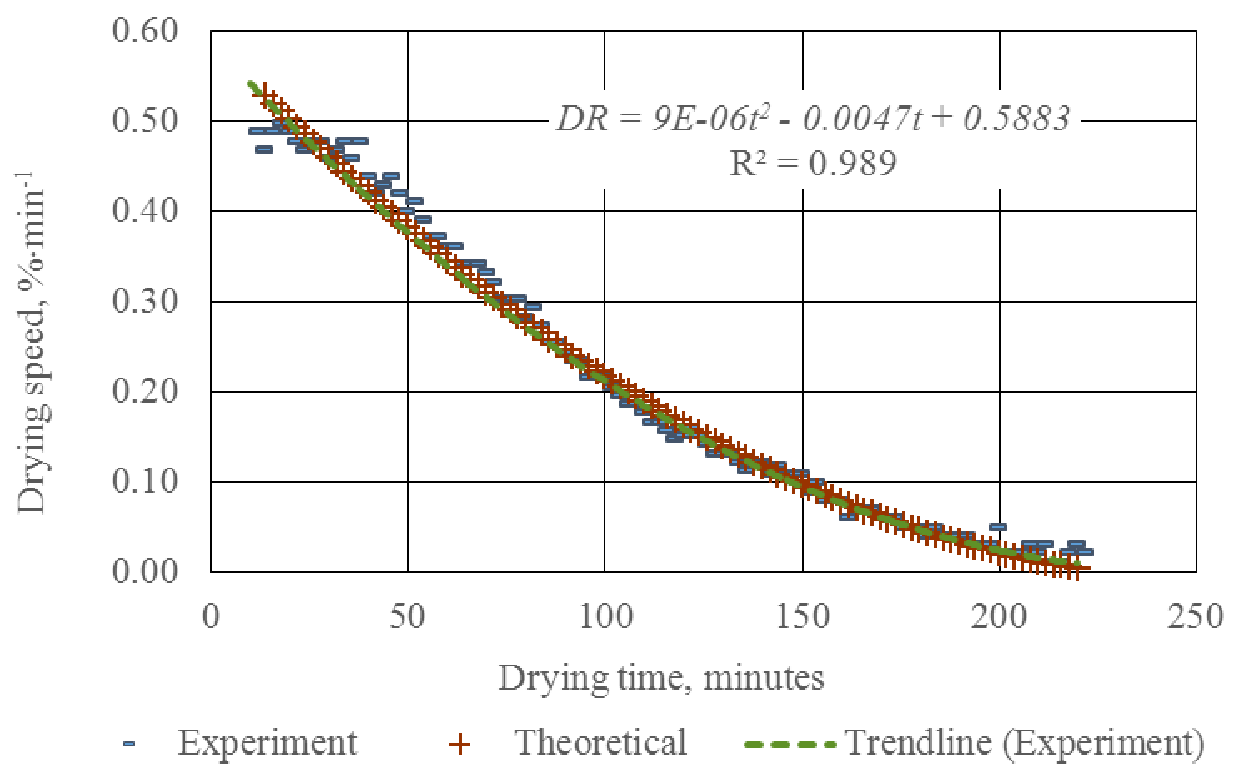

Fig. 5. Drying rate change depending on time at incoming air temperature of $38{ }^{\circ} \mathrm{C}$

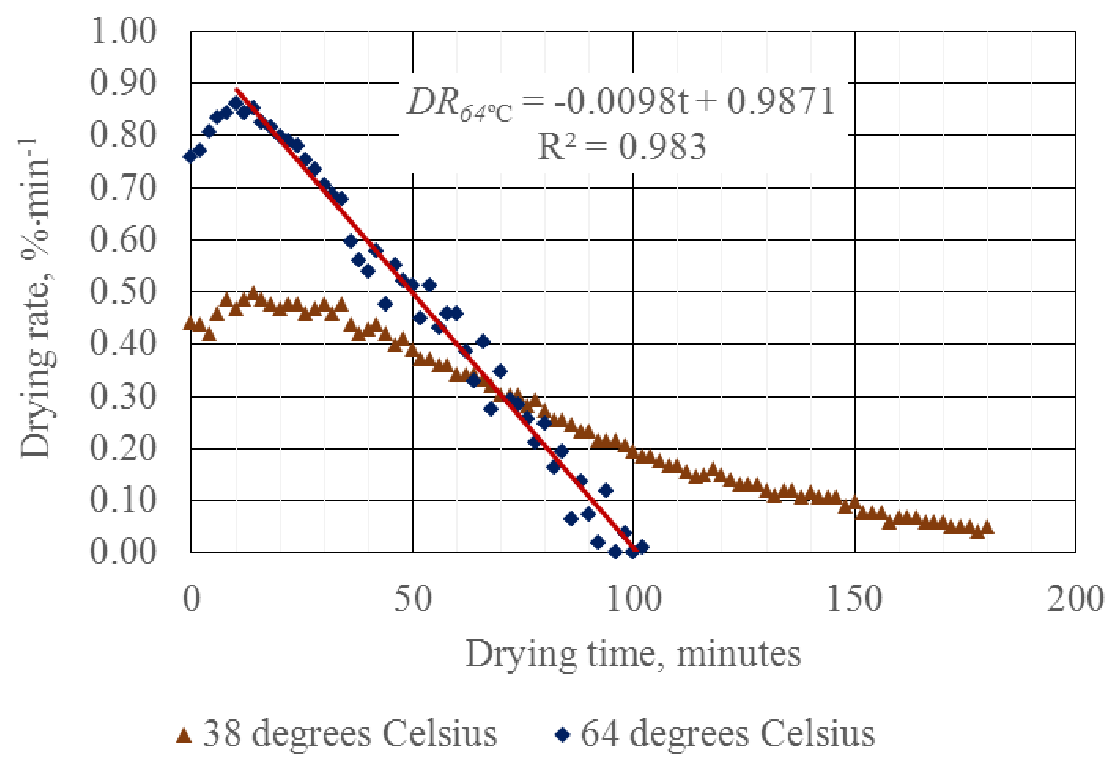

Fig. 6. Drying rate change depending on time for all drying time

In this figure it can be seen that at the beginning of drying the mass warms up and the drying rate gradually increases until it reaches its maximum value. It takes about 10 minutes. Then the process of stationary drying begins and the drying rate gradually decreases. If the incoming air temperature is $64{ }^{\circ} \mathrm{C}$, the drying rate decreases linearly. It describes the linear regression equation shown in Figure 5. The coefficient of determination $R^{2}=0.983$.

In order to preserve the biological activity of vermicompost, drying is necessary to be carried out at the lowest possible temperature. If drying is carried out with the inlet air temperature of $38^{\circ} \mathrm{C}$, the mass heats up to $25^{\circ} \mathrm{C}$ in about 130 minutes (Fig. 3). At this time the mass humidity decreased to $18 \%$ and it is sufficient to perform vermicompost granulation (Fig. 4). 
The drying rate is highly dependent on the drying temperature. Increasing the inlet air temperature from $38{ }^{\circ} \mathrm{C}$ to $64{ }^{\circ} \mathrm{C}$ the maximum drying speed increases twice and reached $0.86 \% \cdot \mathrm{min}^{-1}$. Linear decreasing of the drying rate suggests that vermicompost mainly contains unbound water.

\section{Conclusions}

1. For vermicompost with high moisture content the drying rate is increasing with the rise of the drying agent temperature and decreasing due to the water absence adherent on the surface. The highest value of the drying rate at $64{ }^{\circ} \mathrm{C}$ temperature reaches $0.86 \% \cdot \mathrm{min}^{-1}$ but at temperature $38^{\circ} \mathrm{C}$ it decreases to $0.49 \% \cdot \mathrm{min}^{-1}$.

2. Drying vermicompost at the incoming air temperature $38^{\circ} \mathrm{C}$, the mass inner temperature does not exceed $25^{\circ} \mathrm{C}$ and ensures the preservation of the biological activity of the product. The drying time does not exceed 150 minutes at the air speed in the drying chamber $0.6 \mathrm{~m} \cdot \mathrm{s}^{-1}$.

3. Low drying temperature makes it possible to use solar collectors for air heating and significantly decrease the drying costs.

\section{References}

1. Aira M., Monroy F., Domínguez J. Changes in microbial biomass and microbial activity of pig slurry after the transit through the gut of the earthworm Eudriluseugeniae. Biology and Fertility of Soils, 42(4), 2006, pp. 371-376.

2. Edwards C., Arancon N.Q., Sherman R.L. Vermiculture Technology. Earthworms, organic wastes, and environmental Management. CRC Press, 2010, 623 p. ISBN 9781439809877.

3. Aboltins A., Ruskis G., Palabinskis J. Air Heated Solar Collectors and Their Applicability. Renewable Energy and Energy Efficiency, 2012 pp. 212-217. [online][11.12.2017] Available at: http://llufb.llu.lv/conference/Renewable_energy_energy_efficiency/Latvia_Univ_Agriculture _REEE_conference_2012-212-217.pdf

4. Belessiotis V., Delyannis E. Solar drying. Solar Energy, 85(8), 2011, pp. 1665-1691.

5. Gonzalez J.F. et al. Study of the influence of the composition of several biomass pellets on the drying process. Biomass and Bioenergy, vol. 35, 4399-4406, 2011. [online][11.12.2017] Available at: http://www.sciencedirect.com/science/article/pii/S0961953411004491

6. Vronskis O., Kakitis A., Laukmanis E., Nulle I. Earthworm biohumus conditioning for pellet production. 15th International scientific conference "Engineering for rural development": proceedings, Jelgava, Latvia, May 25-27, 2016 Latvia University of Agriculture. Faculty of Engineering. - Jelgava, 2016. - Vol.15, pp. 997-1002

7. Ozollapins M., Kakitis A., Nulle I. Stalk biomass drying rate evaluation at various layers and drying parameters. 13th International scientific conference "Engineering for rural development": proceedings, Jelgava, Latvia, May 29-30, 2014 Latvia University of Agriculture. Faculty of Engineering. - Jelgava, 2014. - Vol.13, pp. 150-161.

8. Xiao H.Wet. al. Drying kinetics and quality of Monukka seedless grapes dried in an airimpingement jet dryer. Biosyst. Eng. 105, 2010, pp. 233-240.

9. ErenturkaS., Gulaboglua M.S., Gultekin S. The Thin-layer Drying Characteristics of Rosehip. Biosystems Engineering (2004) 89 (2), pp. 159-166.

10. Ndapeu1 D., Njeugnaet E. et. al. Experimental Study of the Drying Kinetics of the Coconut Shells (Nucifera) of Cameroon. Materials Sciences and Applications, 2013, 4, pp. 822-830 [online][11.12.2017] Available at: http://www.scirp.org/journal/msa. 